\title{
On the Distribution of Ash-fall (Meteorological Investigation on the Explosion of Hydrogen Bomb at Bikini Island II.)
}

By

\author{
N. Arizumi \\ Central Meteorological Observatory \\ (Manuscript received 20 May, 1954)
}

\begin{abstract}
The distribution of ash-fall in case of the explosion of hydrogen bomb at Bikini atoll was investigated by using the wind data aloft at Kwajalein and Eniwetok. How atomic dust is diffused in the free atmosphere with time was roughly estimated from the distribution of the ash-fall of Mt. Asama.
\end{abstract}

\section{$\$ 1$. Diffusion of ashes in the atmosphere}

The tests on the diffusion of smoke in the atmosphere near the ground have often been made, but how smoke is diffused in the free atmosphere with time in a large scale have not been cleared up so far. Therefore the diffusion of volcanic ashes will serve as a good reference on this problem.

The distribution of ash-fall in case of the explosion of Mt. Asama on Sept. 23,

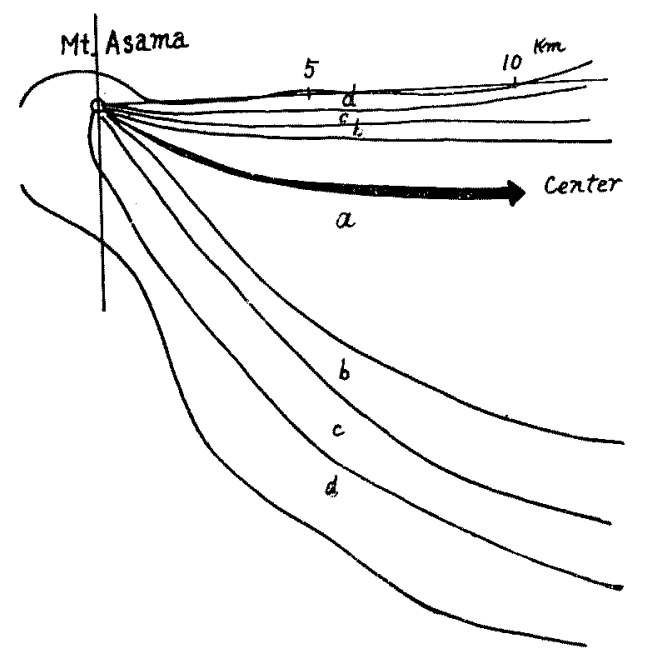

Fig. 1. Distribution of ash-fall $a$ : much $b$ : less $c$ : slight $d$ : trace (After the members of Karuizawa Observatory) 1950, which was investigated by the members of Karuizawa Observatory, is shown in Fig. 1. Fig. 2 shows the hodograph of wind which was observed at Maebashi at $06 \mathrm{~h} 15 \mathrm{~m}$ a few hours after the explosion of the volcano. As the volcanic ashes were blown up $6 \mathrm{~km}$ high

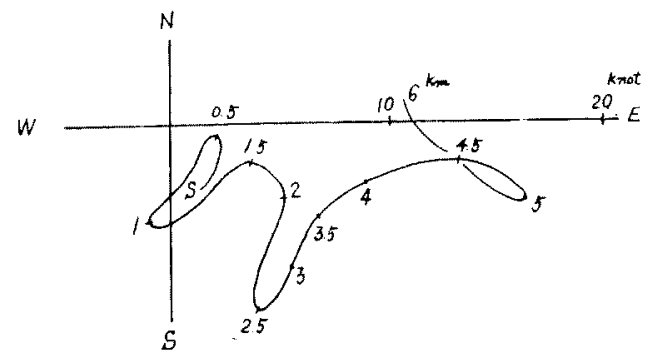

Fig. 2. Hodograph of wind at Maebashi, $06 \mathrm{~h} 15 \mathrm{~m}$, Sept. 23, 1950. 
according to the observation of the smoke at the time, how far the ashes at every $\mathrm{km}$ level over the volcano were blown away by the wind and dropped to the ground without diffusion was calculated from the data shown in Fig. 2. The result is shown in Fig. 3, where the lower long curve and the upper short one are the ash-fall, the

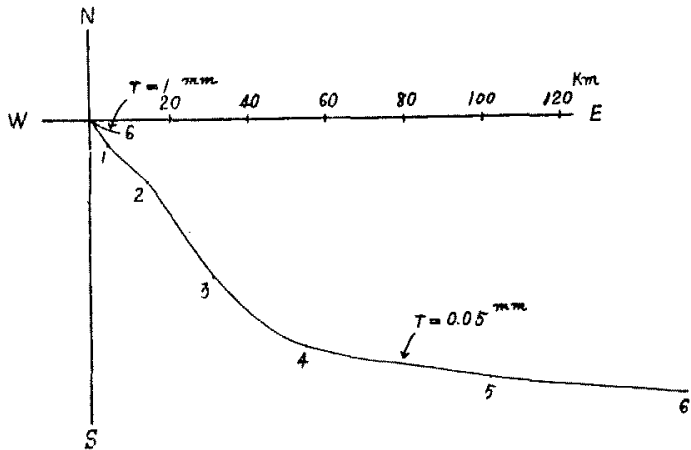

Fig. 3. radii of which are $0.05 \mathrm{~mm}$ and $1 \mathrm{~mm}$ respectively. The fact that the equal concentration curves are more crowded in the northern part than in the southern part in Fig. 1 is due to the change of wind direction with height.

Comparing these curves in Fig. 3 with the distribution of ash-fall in Fig. 1 , it will be reasonable to consider that the ashes were diffused in a width of 20-30 degrees. This value is consistent with that found by Dr. H. Hatakeyama in the spread of smoke due to the big fire in Yokohama in May, 1947. Let us take 20 degrees as the spreading angle of ashes in the following calculations.

\section{$\S 2$. The surface distribution of atomic-ashes}

The component of atomic ashes is $\mathrm{CaCO}_{3}$, but as it is porous because of high temperature at the time of explosion, its density can be assumed seemingly to be nearly $1 \mathrm{~g} / \mathrm{cm}^{3}$. Therefore the descending speed of ashes will be approximately

$\begin{array}{lllllcr}\text { Radius (mm) } & 0.001 & 0.005 & 0.01 & 0.05 & 0.1 & 0.5 \\ \text { Descending speed (cm/s) } & 0.01 & 0.3 & 1.3 & 26 & 78 & 393\end{array}$

If ashes spread out to 50 nautical miles from the center in the horizontal direction and are blown up 80,000 feet high almost at the same time as the bomb exploded (as shown in Fig. 4 and as we saw in the atomic test at Eniwetok in 1952), the surface distribution of ashes, the radii of which are $0.1 \mathrm{~mm}$, on Mar. 1, 1954 is shown in Fig. 4, where $\otimes$ represents the position of Fukuryu-maru No. 5. How $0.05 \mathrm{~mm}$ radius ashes were distributed on the surface on Mar. 1, Mar. 27,

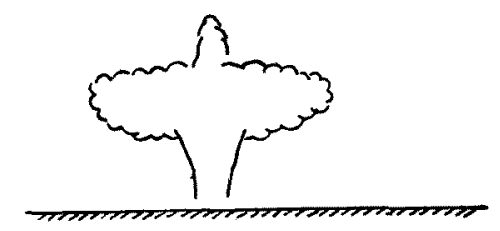

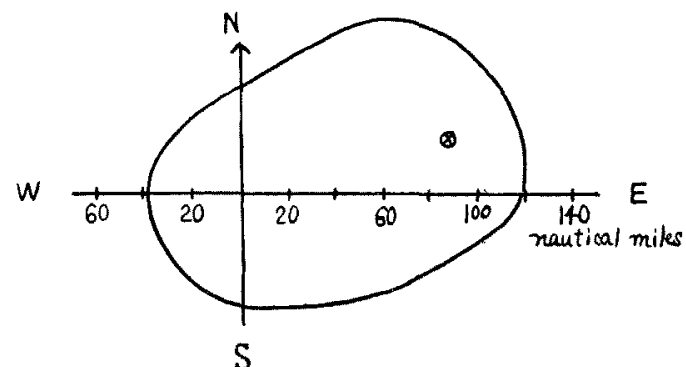

Fig. 4. 
Apr. 6, Apr. 26, and May 5, 1954 was also estimated as shown in Fig. 5.

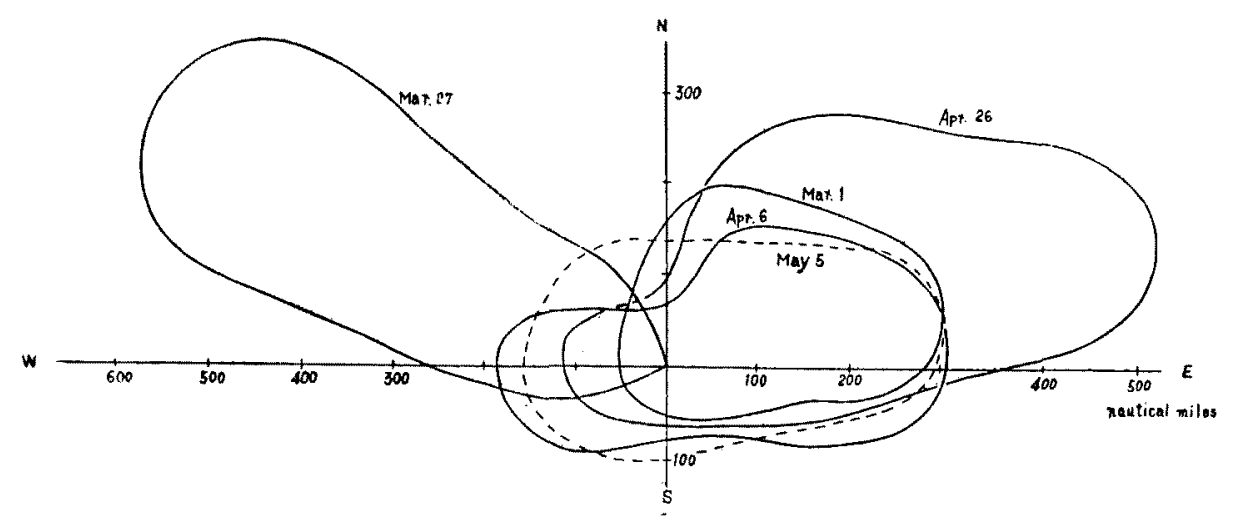

Fig. 5.

A noteworthy fact is that we cannot make hasty conclusion about diffusibility from the distribution of ash-fall as we see in these examples, because ashes can spread out independently with the diffusibility on account of the vertical change of wind aloft; in other words, one of the important factors which determine the distribution pattern of ash-fall is the vertical distribution of wind.

\section{$\S 3$. Danger zone.}

The least concentration of atomic ashes dangerous to a human being is not cleared up yet, but if the quantity of radioactive substance is assumed to be proportional to that of ashes, the region where the ashes, the radii of which are $0.05 \mathrm{~mm}$, is distributed, is directly dangerous to us at least. Because, in case of the test on Mar. 1, 1954, it seems that 28 Americans and 236 natives who lived on Rongelap, Rongerik, and Uterik islands 300 nautical miles away from Bikini atoll had to receive medical treatment according to the report issued by the U.S.A. Embassy. We do not touch upon the indirect evil influence of atomic ashes here.

The author wishes to express his thanks to Mr. H. Ito, Chief of Forecast Section, and Mr. J. Nemoto for their kind advices.

\section{References}

Karuizawa Weather Station, The Eruption of Mt. Asama, Quarterly Journal of Seismology, Vol. 16, No. 2. (1952)

H. Hatakeyama, Kūshū-kasai to Kishō. Tenki to Kiko, Vol. 13. (1947) (In Japanese) 